\title{
Dynamic Simulation of UHMWPE Cable Winding Process of Parallel Grooved Multi-Layer Drum Based on ADAMS
}

\author{
Fankai KONG ${ }^{\text {a }}$, Wenbo CUI ${ }^{\mathrm{a}, 1}$, Fei CHEN ${ }^{\mathrm{a}}$, Zhenyang WANG ${ }^{\mathrm{a}}$ and Zhongchen \\ $\mathrm{ZHOU}^{\mathrm{a}}$ \\ ${ }^{a}$ College of Mechanical and Electrical Engineering, Harbin Engineering University, \\ Harbin, Heilongjiang Province 150001, China
}

\begin{abstract}
According to the insufficient force analysis of the cable in the process of winch retraction, especially the insufficient research on the flexible cable retraction process such as the UHMWPE cable, the dynamic simulation analysis of the retraction process of the parallel grooved multi-layer drum and UHMWPE cable cable is carried out by using the virtual prototype software ADAMS. The simulation model of the cable is created by using the macro command program, and the virtual prototype model of the cable drum is completed, and the force changes of the cable under different rotating speeds are simulated.The simulation results show that the contact force between the cable and the double winding drum can be quickly stable under the specific load, and with the increase of the rotating speed, the maximum value of the tension change of the cable increases, but it is finally stable at a fixed value. The results can provide some reference for structural strength calculation of cable storage drum, selection of high molecular polyethylene cable and dynamic analysis of cable arranger under load.
\end{abstract}

Keywords. ADAMS, UHMWPE cable, parallel grooved multi-layer drum, retraction process, dynamic simulation

\section{Introduction}

The deep sea geological winch system is widely used in deep sea drilling, pipeline laying, resource exploration, geological sampling, equipment towing and other occasions. It has a large amount of cable winding. In the long run, the cables will be worn, disordered and even broken, thus endangering the safety of scientific research equipment and staff [1]. Based on the above considerations, it is particularly important to analyze the force of the cable in the winding process.

In 2013, Dong Dashan compared the three cable modeling methods, which are the substitution of flexible rod, the point mass modeling considering the interaction force and the shaft sleeve force based on the macro command. Through the simulation analysis, it was determined that the cable tension change needs to be paid great attention during the modeling, which provides a reference for the similar cable model in Adams [2]. In 2017, Hu Jingbo took the drum of 34T crane wire rope winch system

${ }^{1}$ Wenbo Cui, College of Mechanical and Electrical Engineering, Harbin Engineering University, Harbin, Heilongjiang Province 150001, China; E-mail: c975665606@163.com. 
as the analysis object, and used ADAMS software to carry out dynamic simulation analysis of lebus drum in hoisting engineering equipment, and obtained the stress characteristics of wire rope through dynamic analysis [3]. In 2017, Kevac studied the dynamic process of the rope winding process, analyzed the change rule of the contact force between the cable and the drum when winding in the same layer, which has an important reference value for the design and optimization of the hoisting system of the offshore winch, and also provides a reference for the establishment of the cable model in this paper [4].

In view of the above problems, this paper selects the double fold cable storage drum, and takes the high molecular polyethylene cable as the sampling cable, uses the virtual prototype technology to establish the dynamic model of the winding of the cable storage drum, reduces the difficulty of the test, and analyzes the force changes of the cable in the process of the winding, so as to provide the theoretical basis for the selection of the cable and the force of the subsequent cable arranger.

\section{The Establishment of Simulation Model of Parallel Grooved Drum}

For the parallel grooved drum, the direction of the cable out of the straight section of the cable storage drum is the same as that of the straight section of the rope groove, which is parallel to the plane where the baffles at both ends of the drum are located, and tangent to the cylindrical plane where the bottom surface of the cable groove of the cable storage drum is located. The exit direction of the cable in the groove of the broken line may be affected by the edge of the groove.

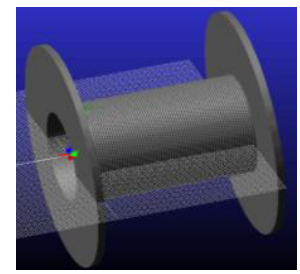

Figure 1. Model of cable storage drum imported into Adams.

The cable storage drum is established by UG NX10.0 and imported into Adams as shown in figure 1.

\section{The Establishment of Simulation Model of Cable}

Because the cable is long and there are many small cylinders after dispersing, the macro command programming can be used in ADAMS to automatically execute the specified command repeatedly, so as to realize the rapid creation of cable model. Generally, the following steps are followed: create the first cell model; place the model with the macro command; move the model with the macro command; add the bushing force with the macro command.

The length and diameter of the cylindrical unit of the cable are $25 \mathrm{~mm}$ and $26 \mathrm{~mm}$. If 500 cylindrical units are taken, the total length of the simulated cable is $12500 \mathrm{~mm}$. 
The cable geometry model created is shown in figure 2 (a). The sleeve force generated automatically by ADAMS macro command is shown in figure 2(b) below.
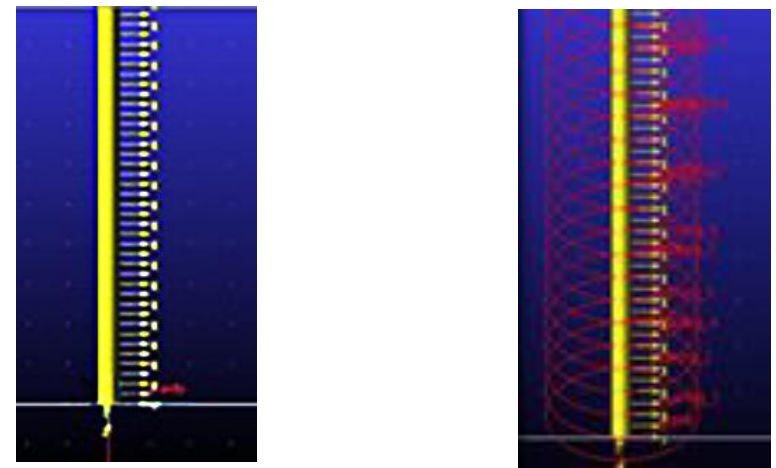

(a) Cable geometry model created by macro command. (b) Cable sleeve force created by macro command.

Figure 2. Modeling process

\section{The Establishment of Virtual Prototype Model}

\subsection{Parameter Calculation of Cable Contact Force}

The winding process of cable and cable storage drum is actually the process of contact, extrusion and collision between cable and cable storage drum. In ADAMS, impact function is often used to calculate the contact force between two objects.

The impact equation is as follows [5].

$$
F_{\text {impact }}=\left\{\begin{array}{lr}
0, & q>q_{0} \\
K_{j}\left(q_{0}-q\right)^{e}+\operatorname{step}\left(q, q_{0}-d, 1, q_{0}, 0\right) c_{\max }(d q / d t), & q \leq q_{0}
\end{array}\right.
$$

Among them, $K_{j}$ is the contact stiffness coefficient; $q_{0}$ is the initial distance of the two components to be contacted; $q$ is the actual distance of the two components to be contacted; $e$ is the collision coefficient of the two objects; $\operatorname{step}\left(q, q_{0}-d, 1, q_{0}, 0\right)$ is the step function in ADAMS; $d$ is the cut in depth of the two objects to be contacted; $c_{\max }$ is the maximum damping coefficient; $d q / d t$ is the speed of the two objects to be contacted.

The contact stiffness is calculated according to the (6).

$$
K_{j}=\frac{4}{3} R^{\frac{1}{2}} E^{*}
$$


Among them, $\frac{1}{R}=\frac{1}{R_{1}}+\frac{1}{R_{2}}, R_{1}$ and $R_{2}$ are the equivalent radii of the two colliding objects; $\frac{1}{E^{*}}=\frac{1-v_{1}^{2}}{E_{1}}+\frac{1-v_{2}^{2}}{E_{2}}, E_{1}$ and $E_{2}$ are the elastic moduli of two colliding contact objects; $v_{1}$ and $v_{2}$ are Poisson's ratios of two colliding objects.

According to the recommended collision coefficient $e$ of ethylene and metal.

The damping coefficient $c_{\max }$ represents the energy loss after contact and collision between two objects. According to the recommended value, the contact between ethylene and metal is $0.68 \mathrm{n}-\mathrm{sec} / \mathrm{mm}$.

The depth of cut in $d$ represents the depth of cut in between two objects after contact under the maximum damping coefficient, which is usually $0.1 \mathrm{~mm}$ in ADAMS.

\subsection{Addition of Cable Contact Force}

The contact force automatically generated by Adams macro command is shown in figure 3 below.

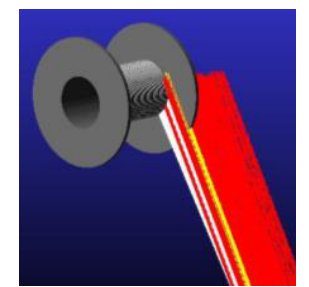

Figure 3. Contact force between cable and drum added by macro command.

\subsection{Application of Loads and Constraints}

\subsubsection{Application of Constraints}

According to the requirements of the project, the load of the cable changes from $200 \mathrm{kn}$ to $5 \mathrm{kn}$ after passing through the traction winch. In the virtual prototype, the load of the cable is simulated by adding a heavy object at the end of the cable. The connection between the cable and the heavy object is carried out through the ball joint as shown in figure 4 (a). The other end of the cable shall be connected with the drum, and the ball joint shall be applied between the first cylinder of the cable and the drum as shown in figure 4 (b) Apply a rotation pair between the drum and the earth.

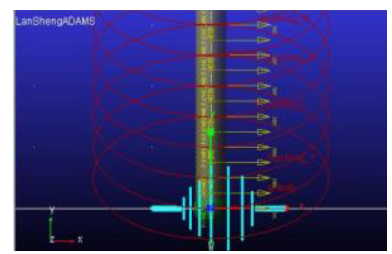

(a) Connection model of cable end unit and load.

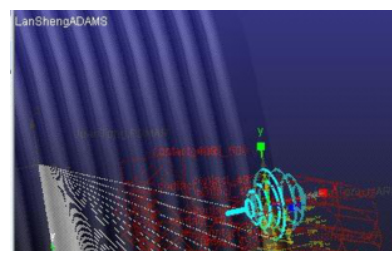

(b) Connection model of cable head unit and drum.

Figure 4. Apply displacement. 


\subsubsection{Application of Driving Force}

According to the requirements of the project, the winding speed of the drum is $0-120 \mathrm{~m}$ / min, and the control accuracy is $1.2 \mathrm{~m} / \mathrm{min}$. When the maximum speed $15120 \mathrm{~m} / \mathrm{min}$, the maximum speed converted to the matching unit in ADAMS is $114.65 \mathrm{deg} / \mathrm{s}$. Assuming that the drum speed is stable after reaching the maximum speed, the stress of the cable at the stable speed is analyzed.

\section{Dynamic Simulation and Result Analysis}

For the virtual prototype model established this time, set the simulation type as dynamics, set the simulation time and steps, and then start the simulation. After the end of the simulation, the post-processing module can be used to analyze the displacement, contact force and sleeve force of the first segment cylinder element, the folded segment cylinder element and the last segment cylinder element of the cable by using Adams's own processor [6].

The drum speed of this simulation is set to 4 speeds between the control accuracy and the maximum speed, which is limited by the computer performance. The simulation parameters and the actual number of loops are shown in table 1 below.

Table 1. Simulation parameter setting.

\begin{tabular}{lllll}
\hline Drum speed (deg/s) & 11.465 & 57.325 & 80.255 & 114.65 \\
$\begin{array}{l}\text { Simulation time (s) } \\
\text { Simulation steps }\end{array}$ & 31.4 & 6.28 & 8.97 & 6.28 \\
$\begin{array}{l}\text { Actual winding } \\
\text { number }\end{array}$ & 1 & 200 & 200 & 200 \\
\hline
\end{tabular}

\subsection{Analysis of the Movement for the cable in the Broken Section of the Rope Groove}

Because the system uses parallel grooved drum for cable storage, the stress of the cable will change dramatically after entering the broken line from the straight line section, so it is necessary to analyze the stress of the broken cable. Starting from the first unit (No. 500 ) of the rope entering the rope groove, unit 473 to unit 455 of the rope are calculated to be the folded section of the rope groove, and unit 473 is selected for analysis.

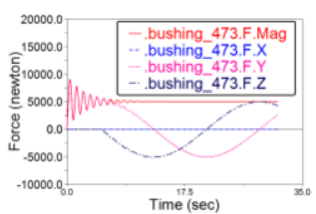

(a) $11.465 \mathrm{deg} / \mathrm{s}$

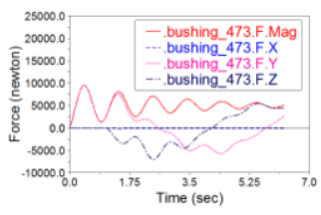

(b) $57.325 \mathrm{deg} / \mathrm{s}$

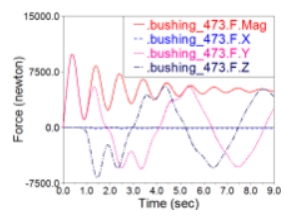

(c) $80.255 \mathrm{deg} / \mathrm{s}$

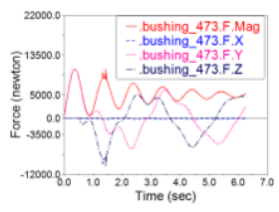

(d) $114.65 \mathrm{deg} / \mathrm{s}$

Figure 5. Three way force of cable unit 473.

From figure 5, it can be seen that the force on three directions of cable 473 unit is 0 before entering the rope groove. After entering the rope groove of broken line section, the value fluctuates and the amplitude decreases gradually. When the cable is wound into the groove, the force of the cable and the friction between the drum begin to offset. The force in the $\mathrm{X}$ direction is very small, which shows that the structure of the cable 
groove fold line is reasonable, and the cable can be arranged in the axial direction smoothly.

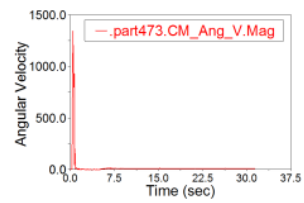

(a) $11.465 \mathrm{deg} / \mathrm{s}$

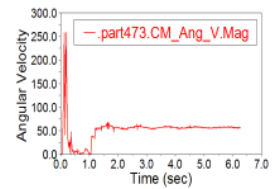

(b) $57.325 \mathrm{deg} / \mathrm{s}$

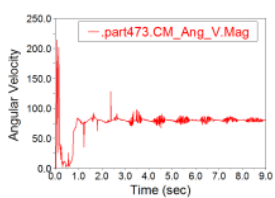

(c) $80.255 \mathrm{deg} / \mathrm{s}$

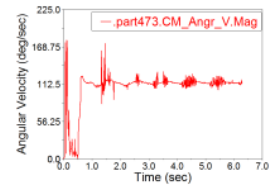

(d) $114.65 \mathrm{deg} / \mathrm{s}$

Figure 6. Cable unit 473 angular velocity.

It can be seen from figure 6 , the angular velocity diagram of unit 473 above that after unit 473 is wound to the cable storage drum, the rotation speed starts to be roughly consistent with the rotation speed of the cable storage drum after fluctuation.

\subsection{Motion Analysis of the First Unit of Cable}

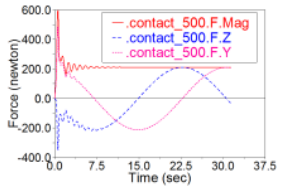

(a) $11.465 \mathrm{deg} / \mathrm{s}$

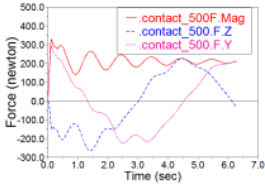

(b) $57.325 \mathrm{deg} / \mathrm{s}$

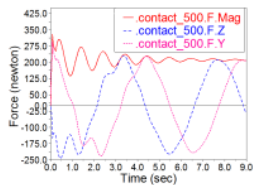

(c) $80.255 \mathrm{deg} / \mathrm{s}$

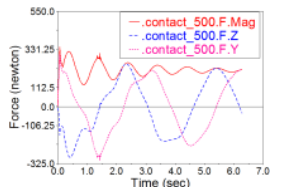

(d) $114.65 \mathrm{deg} / \mathrm{s}$

Figure 7. Contact force of the first unit of cable.

It can be seen from figure 7 that the sudden start causes the cylinder unit of the cable to collide with the drum and then causes the contact force to jump from 0 to the maximum value instantaneously, which plays an important role in the selection of the cable. Subsequently, the fluctuation began to decrease, and finally stabilized at $212.5 \mathrm{~N}$ at four speeds, indicating that the contact force between the cable and the cable storage drum did not change with the change of speed, mainly related to the load of the cable. This value is the pressure of the cable to the first rope groove when the cable storage drum starts to take up the cable, which provides a reference for the structural strength calculation of the cable storage drum.

\subsection{Analysis of the Movement of the End Segment of the Cable}

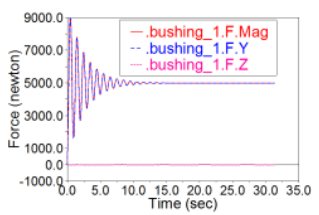

(a) $11.465 \mathrm{deg} / \mathrm{s}$

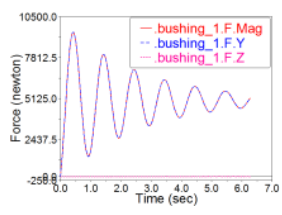

(b) $57.325 \mathrm{deg} / \mathrm{s}$

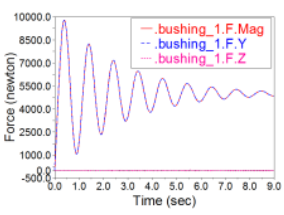

(c) $80.255 \mathrm{deg} / \mathrm{s}$

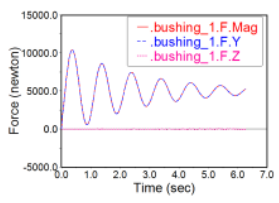

(d) $114.65 \mathrm{deg} / \mathrm{s}$

Figure 8. Cable end unit sleeve force.

It can be seen form figure 8 that the sleeve forces of the cable end unit almost coincide with the sleeve forces of the cable in the $\mathrm{Y}$ direction, which is consistent with the actual situation that the force of the cable is mainly along the cable direction. This shaft sleeve 
force is the tension of the cable. From the above figure, it can be seen that the tension of the cable has a periodic weakening trend.

\section{Conclusion}

In this paper, Adams is used to simulate and analyze the dynamic process of double fold cable storage drum in four rotating speeds: $11.465 \mathrm{deg} / \mathrm{s}, 57.325 \mathrm{deg} / \mathrm{s}, 80.255 \mathrm{deg} / \mathrm{s}$ and $114.65 \mathrm{deg} / \mathrm{s}$. Through the simulation analysis, it can be concluded that:

1) Under the same load but different collection speed, the contact force between the cable and the cable storage drum is stable at $212.5 \mathrm{n}$, which provides a reference for the structural strength calculation of the cable storage drum;

2) With the increase of rotation speed, the maximum value of tension change of the cable increases at the time of coiling. At the maximum rotation speed, the maximum value of tension change reaches $11000 \mathrm{~N}$, but it is finally stable at $5000 \mathrm{~N}$.

The simulation results can provide a reference for the design of slack compensator, a theoretical basis for the selection of high polymer polyethylene cable, and a basis for the dynamic analysis of the cable arranger under load.

\section{Acknowledgment}

The paper is funded by National key research and development program funded projects: (2018YFC0309004). The research is supported by High-tech ship scientific research project in 2018 (emergency evacuation chute systemdevelopment, ministry of industry and information technology packing letter [2017] no. 614).

\section{References}

[1] Guo PA, Mi ZN. Structure design of winch system of underwater lifting profiler. Equipment Manufacturing Technology. 2017 Dec; (12): 216-219.

[2] Dong DS, Sun YG, Liu L. Study on dynamic tension of wire rope based on virtual prototype technology. Machine Tool \& Hydraulics. 2013 Sep; 41(17): 156-158+162.

[3] $\mathrm{Hu} \mathrm{JB}$, Yan JF. Dynamics simulation of crane double-line winding drum based on ADAMS. Mechanical \& Electrical Engineering Technology. 2017 Jun; 46(06): 91-94.

[4] Kevac L, Filipovic M, Rakic A. Dynamics of the process of the rope winding (unwinding) on the winch. Applied Mathematical Modelling. 2017 Aug; 48: 821-843.

[5] Imanishi E, Nanjo T, Kobayashi T, Dynamic simulation of wire rope with contact. Journal of Mechanical Science and Technology. 2009 Apr; 23(4): 1083-1088.

[6] Guo YB, Zhang DK, Chen K, Feng CN, Ge SR. Longitudinal dynamic characteristics of steel wire rope in a friction hoisting system and its coupling effect with friction transmission. Tribology International. 2018 Mar; 119:731-743. 